\title{
Synchronous liver metastases from colorectal origin. Simultaneous or staged resection?
}

\author{
Metástasis hepáticas sincrónicas de cáncer colorrectal. ¿Resección simultánea o \\ diferida?
}

\author{
Gustavo A. Nari'*, Santiago López-Ben², Daniela Mariot', Maite Albiol, Javier Góngora-Ortega and \\ Joan Figueras ${ }^{1}$ \\ ${ }^{1}$ Digestive Oncology Section, General Surgery Department, Hospital Tránsito Cáceres de Allende, Córdoba, Argentina; ${ }^{2}$ Hepatobiliary and Pancreatic \\ Surgery Unit, Department of Surgery, Hospital Josep Trueta, Gerona, Spain; ${ }^{3}$ Department of Statistics, ISEA, Aguascalientes, Mexico
}

\begin{abstract}
Introduction: Between 20 and $40 \%$ of liver metastases from colorectal tumor are synchronous. Three types of surgical approaches are proposed; two of them propose a deferred resection and the other, simultaneous resection. The aim of this analysis is to assess the short- and long-term outcomes of simultaneous resections. Method: 212 synchronous liver metastases resected in two centers were evaluated. Comparison between those resected simultaneously with those that were in a deferred way was made. Demographics, liver resections and metastatic characteristics were evaluated. Morbidity and mortality of both alternatives are also evaluated. Results: 63 patients were resected simultaneously with the primary tumor, there were no significant differences in demographic characteristics. There was a greater number of major resections $(p=0.005)$ in the deferred group. Morbidity and mortality were comparable in both groups. Liver failure $(p=0.037)$ was higher in the deferred group. Morbidity was $33.2 \%$ in the deferred and $10.1 \%$ for the simultaneous $(p=0.256)$. Mortality rate was $2.83 \%$ in the deferred and $0.94 \%$ in the simultaneous group $(p=0.508)$. Conclusion: Short and long-term outcomes for both groups are similar. A question remains to be answered: the need of a major hepatectomy will favor the election of a deferred treatment?
\end{abstract}

Key words: Colorectal metastasis. Synchronous metastasis. Simultaneous resection. Hepatectomies.

\section{Resumen}

Introducción: El 20-40\% de las metástasis hepáticas de origen colorrectal son de tipo sincrónico. Actualmente existen tres estrategias quirúrgicas; dos de ellas proponen resecciones diferidas, y la otra, la resección simultánea. Objetivo: evaluar los resultados a corto y largo plazo de las resecciones simultáneas. Método: Evaluamos 212 metástasis hepáticas sincrónicas resecadas en dos centros y comparamos las intervenidas de forma simultánea con aquellas de manera diferida. Evaluamos las características demográficas, las resecciones hepáticas y las características de las metástasis. También evaluamos la morbimortalidad. Resultados: Fueron resecados de manera simultánea con el tumor primario 63 pacientes, y no hubo diferencias significativas en las características demográficas. Hubo más resecciones mayores $(p=0.005)$ en el grupo de las diferidas. La morbimortalidad fue comparable. La insuficiencia hepática $(p=0.037)$ fue mayor en el grupo de las diferidas. La morbilidad fue del $33.2 \%$ en las diferidas y del $10.1 \%$ en las simultáneas $(p=0.256)$. La mortalidad fue del $2.83 \%$ en las diferidas y del

\footnotetext{
Correspondence:

*Gustavo Nari

Buchardo, 1200

Date of reception: 27-03-2018

Cir Cir. 2018;86(6):648-653

5000 Córdoba, Argentina

Date of acceptance: 20-07-2018

Contents available at PubMed

E-mail: gusnari@ hotmail.com

DOI: 10.24875/CIRUE.M18000081

www.cirugiaycirujanos.com

0009-7411/@ 2018 Academia Mexicana de Cirugía. Published by Permanyer. This is an open access article under the terms of the CC BY-NC-ND license (http://creativecommons.org/licenses/by-nc-nd/4.0/).
} 
0.94\% en las simultáneas ( $p=0.508$ ). Conclusión: Los resultados a corto y largo plazo en ambos grupos son similares. Queda el interrogante de si la necesidad de una hepatectomía mayor favorecería la elección de un tratamiento diferido.

Palabras clave: Metástasis colorrectales. Metástasis sincrónicas. Resección simultánea. Hepatectomías.

\section{Introduction}

Liver resections with curative intent are currently the best option for patients with metastases of colorectal origin. Around $50 \%$ of patients with colorectal cancer will develop liver metastases in the course of their evolution'. Of all of them, 20 to $50 \%$ will do it synchronously ${ }^{2-5}$. Advances in intensive care, anesthesiology, knowledge of liver anatomy and physiology, imaging technology and parenchymal section, as well as the development of new chemotherapeutic agents, have expanded surgical indications for these patients ${ }^{6-11}$.

Until a few years ago, the presence of synchronous liver metastases of colorectal origin was resolved acting first on the colorectal tumor with subsequent chemotherapy, and in patients with good response, removal of the liver metastases was indicated ${ }^{12,13}$. The association of the above-mentioned advances, and the knowledge that contemporary chemotherapy regimens triggered some side effects that increase morbidity and mortality after resection (steatosis, steatohepatitis, sinusoidal dilation and congestion) $)^{14-16}$ have favored the proposal of simultaneous resections of the primary tumor and liver metastases.

The purpose of this work is to assess the shortand-long term results of simultaneous resections in patients with synchronous liver metastases of colorectal origin, with the conviction that there are no differences when compared with those that are carried out in a deferred way.

\section{Method}

Data from patients undergoing liver resection for synchronous liver metastases of colorectal origin in two centers (Hospital Tránsito Cáceres de Allende and Hospital Josep Trueta) between the years 1997 and 2013 (16 years) are analyzed. The results of patients who underwent simultaneous resections are compared with those in whom the resection was carried out in a deferred way. Data were prospectively collected and retrospectively analyzed. Patients with two-stage hepatectomies were excluded from the analysis, as also were those with extrahepatic disease that could not be entirely resected. Standard demographic and clinical-pathological characteristics were collected, as well as data related to the hepatectomies. All patients who received perioperative chemotherapy in previous years had an oxaliplatin and irinotecan-based regimen.

\section{Liver resections}

All patients in whom surgery could remove the entire liver tumor mass, were considered resectable, regardless of the size and number of liver metastases. Major resection was defined as that which involved three or more consecutive segments of the Couinaud classification. The nomenclature used is the one proposed in Brisbane ${ }^{17}$. Liver parenchyma transection was carried out by different procedures, which included the use of Kellyclasia, monopolar and bipolar scalpels, harmonic scalpels and Compact Ultrasonic Surgical Aspiration (CUSA). Liver resection time was measured in minutes from the beginning of the incision until definitive closure of patient skin.

\section{Short-term results}

Those patients who died within the first 30 days, during hospitalization or in a readmission for complications inherent to surgery were considered as postoperative mortality. Morbidity was defined as any adverse event inherent to the surgical procedure, and was classified according to Dindo-Clavien proposal ${ }^{18}$. Liver failure was defined according to the "50-50" criterion $^{19}$. Blood loss was measured in milliliters. Hospital stay was established in days.

\section{Postoperative follow-up}

Patients were followed on a regular basis with laboratory controls, tumor markers and imaging diagnosis. Follow-up and survival control were carried out until patient death or until the date of last control in the office. Survival was determined at 5 years and disease-free survival was measured. The following prognostic factors were evaluated: primary tumor rectal location, presence of positive lymph nodes, presence of extrahepatic disease, metastases bilobar location and presence of more than three lesions. 


\section{Statistical analysis}

Categorical variables were compared with the chi square-test, and continuous variables with the ANOVA system. In the survival analysis, Kaplan-Meier test was used and the differences in survival curves were compared using the log-rank test. Statistical analysis was carried out with the SPSS system, version 20, with a $p$-value $<0.05$ being considered significant.

\section{Results}

Between 1997 and 2013, 599 liver resections were carried out with curative intent for metastasis of colorectal origin; out of them, 212 were synchronous $(35.4 \%)$ and constitute the study universe. One-hundred and forty-nine patients (70.3\%) were intervened in a deferred or classical modality (colorectal resection, chemotherapy and hepatectomy), and 63 patients $(29.7 \%)$ were intervened simultaneously (hepatectomy followed by colorectal resection in the same operative act).

There was a predominance of the male gender. Colonic localization was more common than rectal, as was Dukes' C-type and pT3 stage. The number of positive lymph nodes in both study groups showed no significant differences, as also did the tumor markers prior to hepatectomy. Table 1 details the demographic variables and primary tumor characteristics.

Table 2 shows the variables corresponding to liver resections and metastases characteristics. In it, it can be observed that there were more major resections in the group of patients treated in the classical modality, with a statistically significant difference $(p=0.005)$. The presence of bilobar disease or extrahepatic disease, the number of metastases, resection margin and blood losses showed no statistical differences between both groups.

Deferred resection morbidity was $33.2 \%$, while that of simultaneous resection was $10.1 \%(p=0.256)$. Mortality in the group of patients treated in the classical manner was $2.83 \%$, while in the group of simultaneous surgery it was $0.94 \%(p=0.508)$.

Among the complications that can be seen in Table 3, liver failure showed significant differences between both groups $(p=0.037)$, with a frank predominance in deferred resections (9.9\%). The rest of the complications showed no differences between both groups. In the complication severity analysis, most belonged to groups 2 and 3 of Dindo-Clavien classification (Table 4). As regards the assessment of
Table 1. Demographic variables

\begin{tabular}{lccc}
\hline Variable & $\begin{array}{c}\text { Simultaneous } \\
\text { resection }\end{array}$ & $\begin{array}{c}\text { Deferred } \\
\text { resection }\end{array}$ & p \\
\hline Age & 63.5 years & 63.0 years & 0.619 \\
Male gender & $69.76 \%$ & $70.24 \%$ & 0.544 \\
Rectal primary tumor & $8.86 \%$ & $23.14 \%$ & 0.086 \\
Dukes A & $0.61 \%$ & $1.84 \%$ & 0.823 \\
Dukes B & $3.68 \%$ & $21.47 \%$ & 0.826 \\
Dukes C & $12.88 \%$ & $59.50 \%$ & 0.865 \\
pT1 & $0.56 \%$ & $1.12 \%$ & 0.883 \\
pT2 & $1.12 \%$ & $3.91 \%$ & 0.874 \\
pT3 & $11.73 \%$ & $57.54 \%$ & 0.515 \\
Pre-hepatectomy Ca19-9 & $16.92 \mathrm{U} / \mathrm{ml}$ & $83.08 \mathrm{U} / \mathrm{ml}$ & 0.272 \\
Pre-hepatectomy CEA & $16.23 \mathrm{ng} / \mathrm{ml}$ & $83.76 \mathrm{ng} / \mathrm{ml}$ & 0.914 \\
N+ & $10.92 \%$ & $55.74 \%$ & 0.672 \\
pN0 & $6.18 \%$ & $26.40 \%$ & 0.769 \\
pN1 & $6.18 \%$ & $29.21 \%$ & \\
pN2 & $4.49 \%$ & $27.52 \%$ & \\
\hline
\end{tabular}

Table 2. Metastases and liver resection characteristics

\begin{tabular}{lccc}
\hline Variable & $\begin{array}{c}\text { Simultaneous } \\
\text { resection }\end{array}$ & $\begin{array}{c}\text { Deferred } \\
\text { resection }\end{array}$ & $\mathbf{p}$ \\
\hline Major hepatectomy & $2.83 \%$ & $28.77 \%$ & 0.005 \\
Size & $4.23 \mathrm{~cm}$ & $3.39 \mathrm{~cm}$ & 0.199 \\
Bilobar & $5.5 \%$ & $36 \%$ & 0.275 \\
Number of metastases & 2.81 & 3.98 & 0.595 \\
Extrahepatic disease & $4.48 \%$ & $14.43 \%$ & 0.116 \\
Margin & $0.96 \mathrm{~cm}$ & $0.71 \mathrm{~cm}$ & 0.218 \\
Blood loss & $552 \mathrm{ml}$ & $767 \mathrm{ml}$ & 0.147 \\
Surgery duration & $239.8 \mathrm{~min}$ & $242.8 \mathrm{~min}$ & 0.874 \\
Portal occlusion & $1.41 \%$ & $10.85 \%$ & 0.179 \\
Hospital stay & $11.6 \mathrm{days}$ & $9.4 \mathrm{days}$ & 0.187 \\
Morbidity & $10.09 \%$ & $33.17 \%$ & 0.256 \\
Mortality & $0.94 \%$ & $2.83 \%$ & 0.508 \\
\hline
\end{tabular}

prognostic factors, rectal localization of primary tumor ( $p=0.842$ ), presence of positive lymph nodes in the bowel resection ( $p=0.147)$, bilobar location $(p=0.203)$ and a number higher than three lesions $(p=0.562)$ were not factors of poor prognosis, while the presence 
Table 3. Hepatectomy complications

\begin{tabular}{lccc}
\hline Variable & $\begin{array}{c}\text { Simultaneous } \\
\text { resection }\end{array}$ & $\begin{array}{c}\text { Deferred } \\
\text { resection }\end{array}$ & $\mathbf{p}$ \\
\hline Biliary fistula & $1.89 \%$ & $3.77 \%$ & 0.208 \\
Liver failure & $0.47 \%$ & $9.90 \%$ & 0.037 \\
Intra-abdominal abscess & $3.30 \%$ & $11.32 \%$ & 0.446 \\
Ascites & $1.44 \%$ & $7.69 \%$ & 0.440 \\
Hemoperitoneum & $0.94 \%$ & $6.60 \%$ & 0.332 \\
Infection & $1.89 \%$ & $5.19 \%$ & 0.361 \\
Pneumopathy & $1.42 \%$ & $2.83 \%$ & 0.267 \\
\hline
\end{tabular}

Table 4. Severity of complications

\begin{tabular}{lccc}
\hline Variable & $\begin{array}{c}\text { Simultaneous } \\
\text { resection }\end{array}$ & $\begin{array}{c}\text { Deferred } \\
\text { resection }\end{array}$ & $\mathbf{p}$ \\
\hline Grade 1 & $3.37 \%$ & $12.35 \%$ & 0.202 \\
Grade 2 & $4.49 \%$ & $21.35 \%$ & \\
Grade 3 & $14.60 \%$ & $26.96 \%$ & \\
Grade 4 & $1.12 \%$ & $7.86 \%$ & \\
Grade 5 & $0 \%$ & $7.86 \%$ & \\
\hline
\end{tabular}

of extrahepatic disease $(p=0.048)$ was a poor prognosis factor.

Finally, in the 5-year survival and disease-free survival analysis (Figs. 1 and 2), there were no differences ( $p=0.254$ and $p=0.348$, respectively).

\section{Discussion}

Around $50 \%$ of patients with colorectal cancer will develop liver metastases at some time of their evolution. Between 20 and $40 \%$ of them will be synchronous. Classical approach for these patients has been primary tumor resection and subsequent chemotherapy and liver metastases resection with curative intent. The emergence of new chemotherapeutic agents and their consequences on the liver, associated with a frank improvement in liver surgery results, favored the proposal of tumor and liver metastases simultaneous surgery. On the other hand, Mentha et al. ${ }^{20}$ proposed deferred resection, but in a "reverse" or "liver first" modality. Evaluation of the results of two of the three strategies (classical deferred versus simultaneous) is the purpose of this work.
Two-hundred and twelve patients (35.4\%) who underwent hepatectomy for liver metastases with curative intent belonged to the synchronous group, which is a similar percentage to that reported by other authors, which ranges from 20 to $40 \% \%^{2-5}$. Of the 212 treated patients, 149 (70.3\%) were approached classically, and $63(29.7 \%)$, simultaneously. Dukes' type $\mathrm{C}$ was the most common in both groups, and the number of colonic resections was larger than that of rectal, which is consistent with other experiences. Some authors ${ }^{4,21-23}$ decide the strategy based on the above; rectal location implies greater surgical trauma and would favor the choice of a deferred procedure. The number of major hepatectomies was higher in the classical treatment group ( $p=0.005)$, which is consistent with observations published by other authors and would confirm that in those patients with larger tumor extension avoiding major resections would be attempted ${ }^{4,23-27}$. On the other hand, Yoshioka et al. ${ }^{3}$ report a higher percentage of simultaneous resections $(84.7 \%)$ than ours, with encouraging results, and recommend simultaneous approach. The rest of evaluated parameters, such as blood loss, presence of extrahepatic disease, resection margin, etc., showed no significant differences between both groups and are comparable to those of other series. Hospital stay was similar in both groups $(p=0.187)$ : 11.6 days for simultaneous resections and 9.4 days for deferred resections, which confirms one of the main advantages of simultaneous resections, since in the case of the deferred approach, another admission, another anesthetic procedure and, of course, another abdominal cavity approach are required. Reddy et al. $^{4}$, comparing both strategies, found significant differences between both ( 9 vs. 14 days in major hepatectomies and 8.5 vs. 14 days in minor procedures), and the short stay in favor of simultaneous resection implies economic benefits. Morbidity and mortality in both groups had no significant differences $(p=0.256$ and $p=0.508$, respectively). When each one of the hepatectomy complications was analyzed, we noted that liver failure was higher $(p=0.037)$ in the deferred procedure group; this difference is justified because it is also in deferred procedures where there is a larger number of major hepatectomies. In this work, we did not include the complications inherent to the first surgery in the classical approach, but it could be inferred that their incorporation would have shown a larger number in the deferred strategy group. Reddy et al. $^{4}$ report that overall severe morbidity in both groups showed significant differences in those 


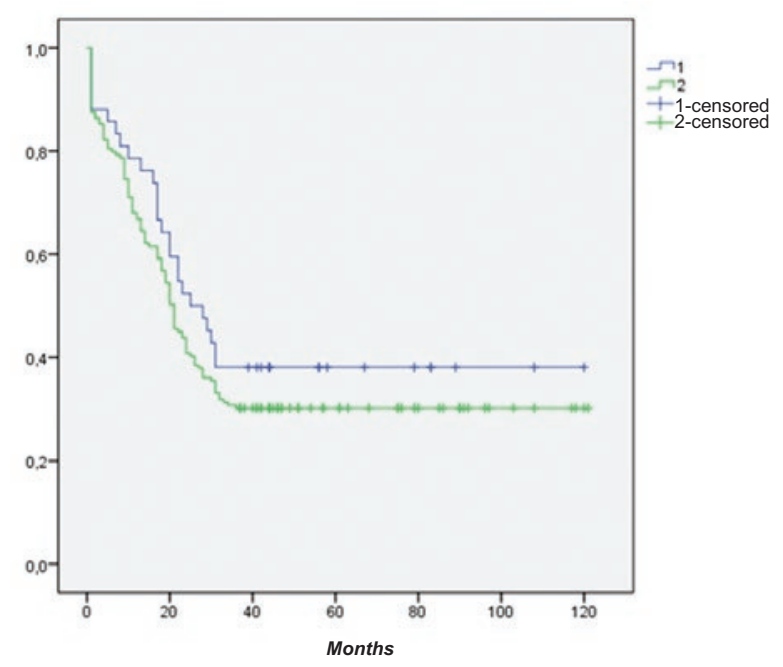

Figure 1. 5-year survival $(p=0.254)$.

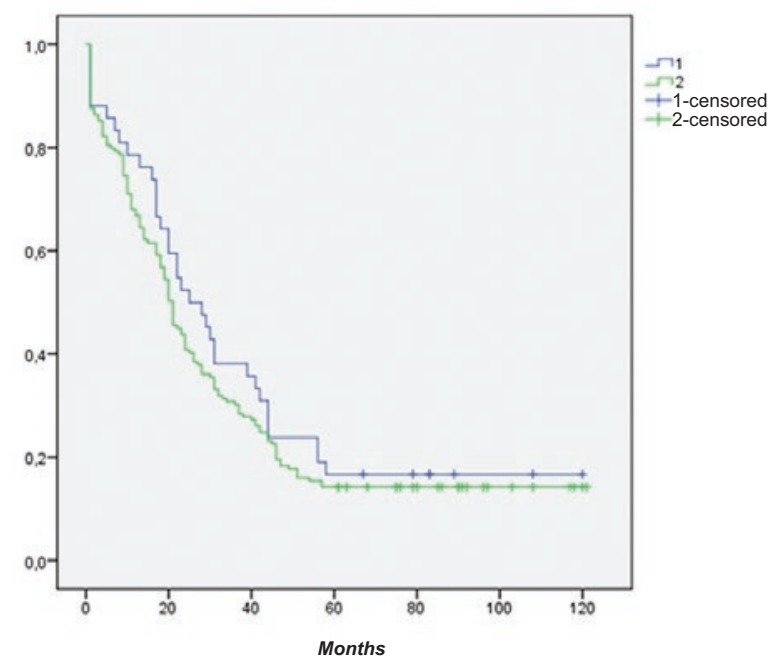

Figure 2. 5-year survival $(p=0.348)$.

patients who required a major hepatectomy in favor of the deferred strategy (36.1 vs. $17.6 \%$ ), while there were no differences when minor procedures were compared; the same results were reported in the studies by Thelen et al. ${ }^{28}$ and Bolton and Fuhrman ${ }^{29}$, and these authors therefore recommend using simultaneous resections only in those patients in whom minor hepatectomies will be performed. In another sense, Martin et al..$^{22}$, Capussotti et al. ${ }^{30}$ and De Santibañes et al. ${ }^{31}$ show that when simultaneous and deferred resections are compared, there are no differences in hepatic or colorectal-origin complications.

The results in terms of survival and disease-free survival with both strategies, as it can be observed in figures 1 and 2, showed no differences, which is consistent with other series ${ }^{13}$. Lykoudis et al. ${ }^{32}$, comparing all the three strategies (colon first, simultaneous and liver first) did not find differences in favor of any, which would reinforce the indication of simultaneous resections.

Some factors have been associated with bad prognosis; primary tumor rectal location has been associated with a worse prognosis than colonic location, but in our analysis of this variable we did not find significant differences $(p=0.842)$. The presence of positive lymph nodes in bowel resection has also been proposed as a poor prognosis factor, but neither did the analysis of this variable yield any difference $(p=0.147)$; it would be worth assessing whether the ratio between positive and total lymph nodes, as it has been proposed for different tumors of the digestive system, could have prognostic implications ${ }^{33}$.

Some authors refer that metastases bilobar location or a number larger than three lesions have negative prognostic implications; the findings in this series do not coincide with the statements expressed by those authors ( $p=0.203$ and $p=0.562$, respectively).

This study has multiple limitations. One of them is that it is a retrospective work with prospectively collected data; another one, perhaps the most important, is the number of years covered by the series, during which patients were applied different parenchymal section procedures and various chemotherapy regimens.

In conclusion, our results show that simultaneous resections of liver metastases of colorectal origin are a procedure with similar morbidity and mortality and survival to those of resections performed in a deferred manner, which would represent a benefit for patients from the point of view of hepatotoxic effects of modern chemotherapeutics as well as an undoubted improvement from the point of view cost-benefit. However, a question would remain that would require to be answered with more certainty: Do major hepatectomies have more morbidity and mortality when performed simultaneously? The answer could determine the admission of a group of patients to a simultaneous surgery protocol, although the trend appears to be to advance towards more aggressive attitudes ${ }^{34,35}$.

\section{Ethical disclosure}

Protection of people and animals. The authors declare that no experiments were performed on humans or animals for this investigation.

Confidentiality of data. The authors declare that they have followed the protocols of their work center on the publication of patient data. 
Right to privacy and informed consent. The authors declare that no patient data appear in this article.

\section{References}

1. Nari G, Moreno E, Feliu L, Azar R, Bonaparte F. Resecciones hepáticas sin tecnología de punta. Ocho años de experiencia. Rev Colomb Cir. 2011;26:48-55.

2. Yin Z, Liu Ch, Chen Y, Bai Y, Shang Ch, Yin R, et al. Timing of hepatectomy in resectable synchronous colo-rectal liver metastases (SCRLM): simultaneous or delayes. Hepatology. 2013;57:2346-57.

3. Yoshioka R, Hasegawa K, Mise Y, Oba M, Aoki T, Sakamoto Y, et al Evaluation of safety and efficacy of simultaneous resection of primary colorectal cancer and synchronous liver metastases. Surgery. 2014; 155:478-85.

4. Reddy S, Pawlik T, Zorzi D, Gleisner A, Ribero D, Assumpcao L, et al. Simultaneous resection of colorectal cancer and synchronous liver metastases: a multi-institutional analysis. Ann Surg Oncol. 2007;14:381-91.

5. Minagawa M, Yamamoto J, Miwa S, Sakamoto Y, Kokudo N, Kosuge T, et al. Selection criteria for simultaneous resection in patients with synchronous liver metastasis. Arch Surg. 2006;141:1006-12.

6. Bismuth H. Surgical anatomy and anatomical surgery of the liver. World J Surg. 1982:6:3-9.

7. González H, Figueras J. Practical questions in liver metastases of colorectal cancer: general principles of treatment. HPB. 2007;9:251-8.

8. Makuuchi M, Takayasu K, Takuma Y. Preoperative trans-catheter embolization of the portal venous branch for patients receiving extended lobectomy due to bile duct carcinoma. J Jpn Surg Assoc. 1984;45:1558-64.

9. Stolz A, Gagniere J, Dupre M, Rivoire M. Destruction locoregionale des metastases hepatiques d'origine colorectale. Place de la radiofrequence. Journal de Chirurgie Viscerale. 2014;151:534-46.

10. De Santibañes E, Clavien J. Playing play-doh to prevent postoperative liver failure. The "ALPPS" approach. Ann Surg. 2012;255:415-7.

11. Grundmann R. Current state of surgical treatment of liver metastases from colorectal cancer. Word J Gastrointest Surg. 2011;27:183-96.

12. Fahy B, Fischer C. Syncronous resection of colorectal primary and hepatic mestastasis. J Gastrointest Oncol. 2012;3:48-58.

13. Mayo S, Pulitano C, Marques H, Lamelas J, Wolfgang C, de Saussure W et al. Surgical management of patients with synchronous colorectal liver matastases: a multicenter international analysis. J Am Coll Surg. 2013; 216:707-18.

14. Vauthey J, Pawlik T, Ribero D, Wu T, Zorzi D, Hoff P, et al. Chemotherapy regimen predicts steatohepatitis and an increase in 90 day mortality after surgery for hepatic colorectal metastases. J Clin Oncol. 2006;24:2065-72.

15. Aloia T, Sebagh M, Plasse M, Karam V, Levi F, Giachetti S, et al. Liver histology and surgical outcomes after preoperative chemotherapy with fluorouracil plus oxiplatin in colorectal cancer liver metastases. J Clin Oncol. 2006;24:4983-90.

16. Karoui M, Penna C, Amin-Hashem M, Mitry E, Benoist S, Franc B, et al Influence of chemotherapy on the risk of major hepatectomy for colorectal liver metastases. Ann Surg. 2006;243:1-7.
17. Strasberg S, Phillips C. Use and dissemination of the Brisbane 2000 nomenclature of liver anatomy and resections. Ann Surg. 2013;257:377-82.

18. Dindo D, Demartines N, Clavien P. Classification of surgical complications. A new proposal with evaluation in a cohort of 6336 patients and results of survey. Ann Surg. 2004;240:205-13.

19. Balzan S, Belghiti J, Farges O, Ogata S, Sauvanet A, Delefosse D, et al. The 50-50 criteria on postoperative day 5: an accurate predictor of liver failure and death after hepatectomy. Ann Surg. 2005;242:824-8.

20. Mentha G, Roth AD, Terraz S, Giostra E, Gervaz P, Andrés A, et al. Liver first approach in the treatment of colorectal cancer with synchronous liver metastases. Dig Surg. 2008:25:430-5.

21. Martin RC $2^{\text {nd }}$, Augenstein V, Reuter N, Scoggins C, Mc Masters K. Simultaneous versus staged resection for synchronous colorectal cancer liver metastases. J Am Coll Surg. 2009;208:842-50.

22. Martin R, Paty P, Fong Y, Grace A, Cohen A, De Matteo R, et al. Simultaneous liver and colorectal resection are safe for synchronous colorectal liver metastases. J Am Coll Surg. 2003;197:23-41.

23. Tanaka K, Shimada H, Matsuo K, Nagano $Y$, Endo I, Sekido $H$, et al. Outcom after simultaneous colorectal and hepatic resection for colorectal cancer with synchronous metastases. Surgery. 2004;136:650-9.

24. Weber J, Bachellier P, Oussoultzoglou E, Jaek D. Simultaneous resection of colorectal primary tumour and syncronic liver metastases. $\mathrm{Br} J$ Surg. 2003;90:956-62.

25. Turrini O, Viret F, Guiramand J, Lelong B, Bege T, Delpiero J. Strategies for the treatment of synchronous liver metastasis. Eur J Surg Oncol. 2007;33:735-40

26. Luo $Y$, Wang L, Chen $C$, Chen D, Huang M, Huang Y, et al. Simultaneous liver and colorectal resections are safe for synchronous colorectal liver metastases. J Gastrointest Surg. 2010;14:1974-80.

27. Abbot D, Cantor S, Hu C, Aloia T, You Y, Nguyen S, et al. Optimizing clinical and economic outcomes of surgical therapy for patients with colorectal cancer and synchronous liver metastases. J Am Coll Surg. 2012;215:262-70.

28. Thelen A, Jonas S, Benckert C, Spinelli A, Lopez-Hänninen E, Rudolph B, et al. Simultaneous versus staged liver resection of synchronous liver metastases from colorectal cancer. Int J Colorectal Dis. 2007; 22(10):1269-76.

29. Bolton J, Fuhrman G. Survival after resection of multiple bilobar metastases from colorectal carcinoma. Ann Surg. 2000;231:743-51.

30. Capussotti L, Ferrero A, Vigano L. Timing of resection of liver metastases synchronous with colorectal surgery. Ann Surg Oncol. 2007;14:195-201.

31. De Santibañes E, Lasalle F, Mc Cormack L. Simultaneous colorectal and hepatic resections for colorectal cancer: postoperative and long-term outcomes. J Am Coll Surg. 2002;195:196-202.

32. Lykoudis P, O'Reilly D, Nastos K, Fussi G. Systematic review of surgical management of synchronous colorectal liver metastases. BJS. 2014; 101:605-12.

33. Nari G, Palacios O, López Ben S, Albiol M, Falgueras L, Castro Gutiérrez E, et al. Hilar cholangiocarcinoma: the number of positive nodes and positive node/total node ratio is a significant prognostic factor for survival. Cir Esp. 2014;92:247-53.

34. Karoui M, Vigano L, Goyer P, Ferrero A, Luciani A, Aglietta M, et al. Combined first stage hepatectomy and colorectal resection in a two stage hepatectomy strategy for bilobar synchronous liver metastases. $\mathrm{Br}$ J Surg. 2010;97:1354-62.

35. Andres A, Mentha G, Adam R, Gerstel E, Skipenko O, Barroso E, et al. Surgical management of patients with colorectal cancer and simultaneous liver and lung metastases. BJS. 2015;102:691-9. 